\title{
Towards Information and Knowledge in Product Realization Infrastructures
}

\author{
John J. Mills, Jan Goossenaerts \\ Group Information Technology, Faculty Technology Management, The Technical University \\ Eindhoven, Eindhoven, The Netherlands.
}

Keywords Product Realization, Knowledge, Information Infrastructures

\begin{abstract}
For many decades now, the focus in information technology to support the product realization process has been on data: its creation, management, and use. A general sense is emerging that data alone is no longer sufficient to support the people involved in this process. In this paper we suggest that it is time to start understanding what Knowledge is necessary to the product realization process and to move towards thinking of and implementing knowledge infrastructures and product knowledge managers. The authors provide some definitions of data, information, and knowledge in general and show how it relates to information and data. Specifically, we highlight the importance of (a) relationships or patterns in data and information, and (b) context to understanding knowledge. As part of our definitions, we provide some brief examples of relationships and contexts in the product realization process and show that the manufacturing community has already started to manage knowledge in the product realization process.
\end{abstract}

\section{INTRODUCTION}

As products become more sophisticated and complex, and computers are used to perform more and more tasks during the product realization process, it is becoming clear that current approaches to managing the representation of the product do not support the realization team well. Product data managers (PDM's), for instance, do not provide adequate support for either designers or production planners.

While there is work on defining what the next generation of PDM's should look like [1], there is also a growing realization that managing the product data alone is not sufficient. As Thoben et al have said: "...a learning organization requires the management of product data and knowledge." Several authors have started to address the issue of managing the knowledge created during the realization of the product and specific methodologies are 
beginning to emerge $[1,2]$. Further, there is increasing attention being paid to managing knowledge as a corporate asset $[3,4]$. However, it is not at all clear what is meant by "product knowledge" or by "knowledge" in the Product Realization Process (PRP). Discussion of "knowledge" in the literature ranges from the philosophical (i.e. epistemology [5]) to vague general descriptions. In this paper, we provide a perhaps more pragmatic approach to defining and understanding what knowledge is and what product knowledge might be. In particular, we show that context and interrelationships are a neglected but very important aspect of knowledge in general and product knowledge in specific. In this discussion we draw on examples of data, information and knowledge from the product realization process and show that, as a community, we have already started along the path of creating knowledge infrastructures and product knowledge managers.

\section{DATA, INFORMATION AND KNOWLEDGE}

\section{Data}

There appears to be general consensus in the literature on the definition of data but that the definitions for information and knowledge vary considerably. Data are simply symbols (e.g. numbers) with no context and no relationships $[6,7,8]$. For instance, the separate characters, "1.2,""3.4", "in.," "C," "A," and "B" are just data. In the product realization process, data is just the numbers and symbols used in describing, for instance, a line, a vertex, the material used, the machine capacity. Other data is required and relationships must be identified before these numbers and symbols can be interpreted as lines, vertices, etc..

\section{Information}

Information has been variously defined as: 1) a quantitative measure of the content of information [6]; 2) consisting of processed data, the processing directed at increasing its usefulness [7]; 3) the result of comparing data that are structured to provide a meaning within a given context [8].

Information exists when we recognize relationships in data within a specific context. The symbols "1.2", "in.", and "B" taken independently, do not mean much to anyone. They are just data. Stated as "1.2 in. from B," most people would understand this relationship as a distance from a location, "B". Written this way, these symbols impart meaning to the reader. Looked at another way " 1.2 in. from B" is a pattern that the mind recognizes and associates with other patterns stored in long term memory.

In general terms, therefore, when patterns or relationships can be 
discerned in data, we have information and meaning is given to data: the brain is able to (a) perceive the patterns, (b) match them to patterns which it has stored and (c) connect them to other patterns. This perception of the pattern and its matching and connection to existing patterns we call recognition and understanding.

As another example of information, an ASCII view of a STEP or IGES file is just a list of numbers or just data, but when this data is read by a software program than can interpret each number or symbol according to a data model which determines the relationship between the numbers, and display this relationship on a computer screen, the user recognizes the relationship as a geometric shape. The recognized relationship between the numbers makes them information. Given a different data model or context in the relationship might end up meaning something else. This is where information begins to become knowledge.

\section{Knowledge}

Knowledge is much more difficult to define because it has so many possible interpretations as illustrated by the entry in Webster's Dictionary [6]. In what follows we avoid delving into epistemological arguments about knowledge and attempt to stay on a more practical level. First, there is the definition (in Webster's) in terms of "the sum of what is known" or "the body of truth, information and principles acquired by mankind." [6] It is the collective knowledge of mankind. We call this "Total Knowledge" and it exists mostly in a very diffuse, not very useful state. Part of this Total Knowledge can be codified or made explicit while the rest will remain locked up in the brains of humanity until ways can be found for extracting it from individual human minds. This event is not likely in our lifetime.

The individual contributions to Total Knowledge are what Polanyi has termed Personal Knowledge [9]. As Polanyi has suggested, part of Personal Knowledge is Tacit and part is Focal [9]. While Tacit Knowledge can play a substantial role in decision making and problem solving in the product realization process, it is hard to provide information technology support for it. Nonaka and Takeuchi have suggested ways in which tacit knowledge can be usefully tapped in product realization teams [3].

Tacit knowledge is the sum total of a person's experience and training and includes parts which cannot be articulated by the person. As Polanyi has put it " We know more than we can say." [9]

According to Polanyi [9] and Weggeman [8], Focal Knowledge is knowledge that is applied to a specific task. Focal knowledge encompasses codified or explicit knowledge. The codified part of focal knowledge is the knowledge we can usually articulate in some form. From these definitions, it 
should be noted that "codified knowledge" and "explicit knowledge" are the same. This is the personal knowledge which can be written down in some form or other. The rest of our focal knowledge, we cannot make explicit, at least at that point in time. Figure 1 illustrates our suggested relationships between these different types of knowledge.

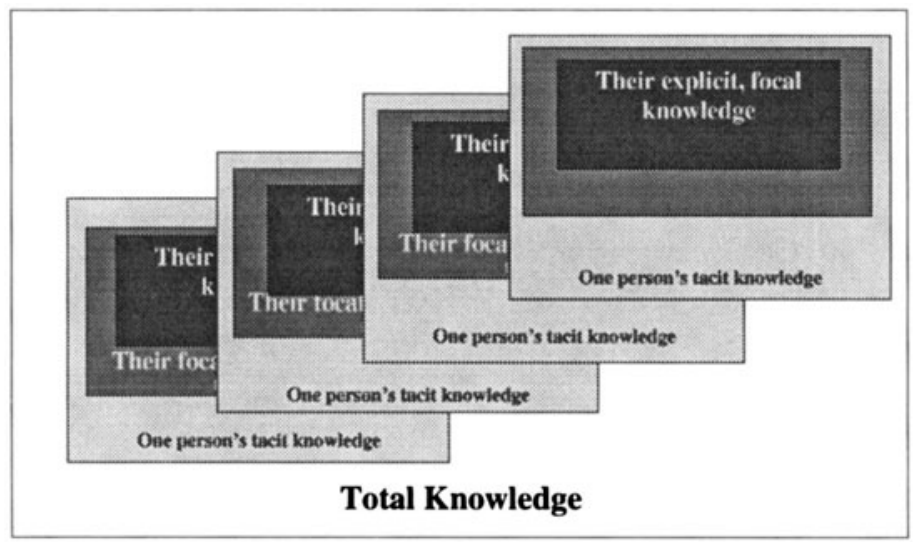

Figurel. Proposed relationship of the different kinds of knowledge to each other

To view knowledge from a different perspective, we examine the mechanism by which data becomes information becomes knowledge. In our view, the mechanism by which a string of symbols becomes information is recognition and understanding or comprehension. Understanding and comprehension are used interchangeably here. First, a pattern is recognized within a particular context, then internalized (or indwelling as Polanyi calls it [9]). In this recognition process, the pattern in the data is matched with an existing pattern within its context creating information.

When a person recognizes and understands complex patterns in data (i.e more complex than the relationships which create information) and in information itself, knowledge is created. In the understanding (Polanyi's indwelling) process, connections are made in the mind to other, related patterns (i.e. personal information and knowledge) in the same context. When appropriate connections are made, the person "understands" the information, and it has meaning for them: it becomes knowledge.

In another method of creating knowledge, a person connects patterns, recognized in information within a specific context, to similar patterns in other contexts and then, recognizing and internalizing that pattern across contexts, creates knowledge in their mind. They also create knowledge when that recognized pattern is used in other contexts. The pattern " $\mathrm{F}=\mathrm{ma}$ " by itself is simple information. The understanding that the pattern " $\mathrm{F}=\mathrm{ma}$ " can be applied in predicting the motion of sub atomic particles, atomic 
particles, human sized bodies (e.g. a car), space craft, planets, star systems, galaxies, each of which is a different context, creates knowledge.

Moreover, knowledge can be also created from other knowledge. For instance, Newton had access to all the codified knowledge of his peers and predecessors on the motion of bodies but only he was able to see a pattern which resulted in his equations and theory of motion thereby creating new knowledge. Similarly, Planck was able to see patterns in available codified scientific knowledge that allowed him to formulate his Quantum Theory.

Hence, knowledge is created or exists when (a) complex patterns are recognized and understood in data, (b) patterns are recognized in the simple relationships of the information and these patterns extend across several contexts; and (c) patterns are recognized in existing knowledge itself.

This leads naturally to the concept of Re-ification in which the mind collects all the knowledge about a concept under a single "thing" or Res [10]. As suggested by Wilson, reification involves taking a complex set of knowledge and making it into a single entity. This "Res" can then be incorporated into other concepts of greater complexity, leading to a layering of knowledge as suggested by Feynman and Polanyi. Feynman's layering seems to be mostly hierarchical [11], but both Polanyi and Wilson indicate that the connections between layers is much more complex than a simple hierarchy with connections within layers and multiple connections between layers $[9,10]$. This leads to the idea of what we call connectedness or the degree of connectivity among concepts or Res. Our current hypothesis is that the degree of connectivity is related to the complexity of the relationships existing within knowledge and hence to the level of knowledge.

Knowledge, therefore, comes into existence with the recognition and understanding of patterns and how they can be used in tasks like problem solving and predicting phenomena across a wide variety of contexts at increasing levels of complexity. As Polanyi has said; the true knowledge of a theory "lies in our ability to use it." [9] Since context independency and connectedness appear to be two parameters that define knowledge it seems natural to use a graph to provide a framework for describing knowledge, Figure 2. The large arrow indicates the transformation of data into information and information into knowledge etc. This figure is derived from a similar figure by Bellinger [12]. The difference is discussed below.

Since all knowledge is ultimately personal, there must be some human factor in this graph. What makes knowledge personal is a person's abilities. It seems to us that the greater the person's capacity for identifying, storing, matching and connecting patterns, the greater their ability to create knowledge of greater connectedness and context independence. This view recognizes the ability of some people to recognize significant patterns in a 
lot of noise and to be able to make good decisions in the presence of uncertain information. We call this ability "Innate Intelligence" for want of a better phrase at this time.

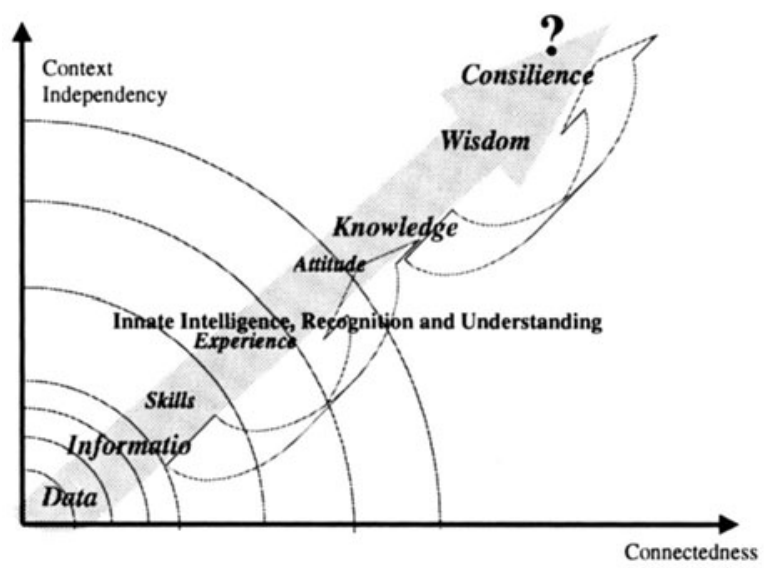

Figure 2. Concept of knowledge as a function of context independency and connectedness

Consider the example of Planck given above. Although the information and knowledge that Planck used to create Quantum Theory was available to a wide variety of scientists, only he had the "Innate Intelligence" to recognize the pattern in all the existing information and knowledge, much of which was not relevant and hence was probably noise from his viewpoint [9]. Innate intelligence must be applied to create higher levels of knowledge. Thus, these words appear in the mechanism by which data , information and knowledge move to higher levels as indicated by the curved arrows.

In this diagram, a natural issue arises: when does information become knowledge and what role does context play in this transition? It is not clear to us that this is a useful debate. It seems to us that there is a broad grey area in which information might be data and knowledge might be information.

The data-information-knowledge space is in one sense continuous with no abrupt barriers between them. Data merges into information into knowledge etc and one person's knowledge may be another's information. It seems to us that, because of the way the human mind works, there is no sharp dividing line between data and information and between information and knowledge. However, this space is structured into various levels, in which each level can merge into the next by means of the application of a human's innate intelligence. In Figure 2, therefore, data occupies a very small circle - the lowest level - around the origin. Information occupies a larger circle encompassing the data circle, but the actual boundary to data is 
uncertain. Knowledge occupies a much larger circle but its boundary to the information also extends over a broad range.

As discussed earlier, we think that the space illustrated in Figure 1 can either represent Total Knowledge for mankind or a single person's focal or tacit knowledge. However, none of the above really discusses what Knowledge is and while helpful in understanding what product knowledge might be, it does not move us very far forward in determining how we can help engineering teams make better products. Another perspective of Knowledge is that explicit or codified knowledge has been described as facts, procedures, rules, images, etc. However, facts, procedures, and rules can also be formatted as patterns or relationships. Hence, knowledge, as far as we can tell, is all about relationships and contexts.

\section{KNOWLEDGE WITHIN THE PRODUCT REALIZATION PROCESS}

However, in this paper we do not discuss the management of tacit knowledge or even focal knowledge, but only the codified part of focal knowledge because that is what is created, transferred and used in the product realization process using computer systems. Further, space precludes our discussing the myriad relationships and contexts in any detail.

Modern products are complex, sophisticated artifacts with manifold relationships. The idea of managing the relationships among product data is not new. As long ago as 1988, Wasserman was highlighting the importance of this topic [13]. The first and most obvious of all product system relationships is that between the geometric entities of the physical embodiment of the product structure. Modern CAD systems are already managing these relationships quite well and provide tools to the users to identify and understand them. For instance, most CAD systems provide visualization of the geometry in a variety of forms (e.g. line, hidden line, surface. 3-dimensional, etc). Modern CAD systems also allow users to manage another form of relationship, namely constraints between geometrical entities, as in Parametric or Variational Design. They also typically allow the user to manipulate a third kind of relationship: the bill of materials or product structure. Product data managers (PDMs) also manage the bill of materials (BOM) and are starting to provide multiple contexts for it: engineering, vs. production vs. procurement. PDM's typically also allow relationships among versions, and alternatives to be managed. Some PDM's are also beginning to allow users to work with a fourth kind of product relationship, that of the product family. To manage the product relationships along the product realization process some companies are introducing 
workflow management systems and PDM vendors, responding to the trend are incorporating such systems into their products. Workflow management tackles the management of the life cycle relationships in product realization.

As an alternative to this approach to life cycle relationship management, several researchers are suggesting that we need to define all the product information and the interrelationships of this information in a single product schema. This purpose-function-behavior-embodiment relationship, first suggested by Gero [14], expanded by Rosenman and Gero [15] and then further by Wang and Mills, can be called abstraction-concretization relationship because, as one moves from purpose to function and on to the physical embodiment, the level of abstraction decreases and the amount of concrete detail increases. Others have provided slightly different versions of the representation of a product schema [16,17]. Szykmann et al actually provide a relationship object within their schema [17]. Another approach to capturing and understanding the complex relationships in a context independent manner is that of Goossenaerts [2]. His artifactual wheel-work $(A W W)$ systematises product life-cycle related concepts in order to derive generic requirements for product life-cycle support services in a ubiquitous information infrastructure. For the life cycle of artifacts and their groupings, a distinction must be made between three kinds of existence: (i) the individual or ens, e.g., your car; giving rise to the ontogenic wheel (ii) the type (in the case of things, e.g., the type of your car) or generation (in the case of self-reproducing species), giving rise to the typogenic wheel; and (iii) the tribe or family (phylo), e.g., the totality of previous and actual types and occurrences of your car, or of all cars, giving rise to the phylogenic wheel.

These wheel works represent true product realization knowledge because they capture the complexity of the relationships in the product realization process and are also context independent. They apply equally well to the realization of aircraft, automobiles, kitchen mixers or software.

Within these relationships, there is another example, namely that relating the decisions made at each stage to the appropriate product values and to the rationale behind those decisions. While it is generally recognized that rationale is important to product re-use, it is not as clear, how it should be incorporated. Wang and Mills have incorporated rationale in their Collaborative Product Representation Model (CPRM), which is essentially a product knowledge schema [18]. This preliminary schema also includes a re-use module which exports the internal methods and data required for appropriate re-use of this component by others, another form of relationships.

Contexts are more difficult to deal with and are typically implicit. Websters Dictionary has several definitions, the most appropriate of which 
are: "the interrelated conditions in which something exists or occurs"; and "things or conditions that serve to date or characterize an article" [6]. One way we are exploring for representing context in Information Infrastructures is to think of them as a set of environmental parameters that condition how a tool works. Most operating systems, word processors, and CAD software packages provide accommodation for different cultures and preferences which are a type of context. Hale has suggested that documents created during the PRP require a simple type of context such as a date, name of the person involved, the number of the iteration and the tool used to create it [19]. A well known problem in the product realization process which might be possible to solve by considering context is that of multiple Bills of Material: engineering, manufacturing, procurement, etc. Basically, each view is of the same information but in a different context. The proper management of context is an unsolved issue in the management of knowledge.

\section{DISCUSSION AND CONCLUSIONS}

Our pragmatic view of knowledge in the product realization process is that it is the relationships in product and process data and information within and across contexts that is as important if not more important than the data itself. This is why CAD systems, PDM's and workflow managers have implicitly started managing them. Each of these separate systems manage only limited relationships and rarely involve contexts. One conclusion, therefore is that we need more comprehensive approaches to managing the manifold relationships in the product realization process. Before that can be achieved however, we need to explicitly identify all the myriad relationships in a meaningful way. The artifactual wheelworks of Goossenaerts might be one approach to addressing this issue.

A second conclusion is that we need to find ways of identifying and taking advantage of contexts. Use of contexts is a natural and powerful mechanism we use implicitly every minute of every day. If we can harness this power in our information infrastructures for manufacturing, we will take the use of information system to new heights.

\section{REFERENCES}

[1] K.-D. Thoben, Wognum, P.M., Pels, H. J., Büchner, A.G., Goossenaerts, J.B.M., Ranta, M., Ranke, A.A.M., Gibbons, W.M., Kerssens-van Drongelen, I.C., "From Product Data to Product Data and Knowledge Management - Requirements and Research Perspective".

[2] Goossenaerts, J.B.M., "Industrial Semiosis: Founding the deployment of the Ubiquitous Information Infrastructure,” Computers in Industry, to appear, 2000. 
[3] Nonaka, I., Takeuchi, H., "The Knowledge-Creating Company," Oxford University Press, New York, Oxford, 1995.

[4] Drucker, Peter F., "Post-Capitalist Society,". New York: Harper Business Press, 1993.

[5] Audi, Robert, "Epistemology: a contemporary introduction to the theory of knowledge," published by Routledge, London, 1998.

[6] Webster Ninth New Collegiate Dictionary, Merriam-Webster Inc, 1990.

[7] Ackoff, R, "Ackoff's Fable,: Irreverent Reflections on Business and Bureaucracy," John Wiley and Sons, New York, 1991.

[8] Weggeman, M., "Knowledge Management: The Modus Operandi of the Learning Organization" Published in Knowledge Management: Organization, Competence and Methodology, Proc of the $4^{\text {th }}$ International ISMICK Symposium, Rotterdam The Netherlands, Erlon Verlag, October, 1996

[9] Polanyi, M., "Personal Knowledge: towards a Post-Critical Philosophy", Harper Torchbooks, New york, 1964.

[10] Wilson, P., "Consilience”, Random House publishers, 1999.

[11] Feynmann, R., cited in Davis, God and the new physics, Simon \& Schuster publishers, pp 223-225, 1983.

[12] Bellinger, G., Castro, D., and Mills, A., unpublished article to be found at URL = http://www.outsights.com/systems/dikw/dikw.htm.

[13] Wasserman, A.I., "Tool Integration in Software Engineering Environments:" Proc. Int'l Workshop on Environments, F. Long ed., Springer-Verlag, Berlin, pp 137-149, 1990.

[14] Gero, J., "Design Prototypes: A Knowledge Representation Schema for Design", AI Magazine, Winter, 1990, pp26-36.

[15] Rosenman, M. A. and Gero, J. S., "Modelling Multiple Views of Design Objects in a Collaborative CAD Environment”, Computer-Aided Design, Vol.28, No.3, pp.193-205, 1996.

[16] Henderson, M. R., "Representing Functionality and Design Intent in Product Models", in $2^{\text {nd }}$ ACM Solid Modelling '93, Montreal, Canada, 1993.

[17] Szykman, S., Fenves, S. J., Keirouz, W., and Shooter, S. B., "A foundation for Interoperability in Next Generation Product Development Systems," To be published in Computer Aided Design, Special Issue on Product Data Representation and Management, 2000.

[18] Wang, F., and Mills, J.J. "A Product Data Model and Processor Supporting Virtual Product Development," The ASME Design Engineering Technical Conference and Computers and Information Conference, Baltimore, Maryland, September 10-14, 2000.

[19] Hale, M., Georgia Institute of Technology, Presentation to the Gordon Conference on Theoretical Foundations for Product Design and Manufacturing, New Hampshire, June 11-16, 2000.

\section{ACKNOWLEDGEMENTS}

The authors would like to thank the National Science Foundation for funding under, the Agile Aerospace Manufacturing Research Institute Grant No DDM 9320949 and the Information Technology Group of the Technology Management Faculty of the Technical University of Eindhoven, for hosting Dr Mills during the writing of this paper. 